\title{
НЕПОЛЯРНЫЕ УГЛЕВОДОРОДЫ ДОННЫХ ОСАДКОВ БАЛТИЙКОГО МОРЯ
}

\author{
(Представил И. Эпик)
}

Нефтяные углеводороды, попадая в водную среду, адсорбируются на частицах взвеси или же аккумулируются в биологическом материале и вместе с ними оседают на дно водоемов. Здесь они, накапливаясь и претерпевая дальнейшие превращения, загрязняют придонную воду и оказывают токсическое действие на донную фауну. В условиях низких температур, малых содержаний кислорода и без доступа солнечного излучения состав донных отложений претерпевает изменения крайне медленно (в отличие от динамичной водной системы, уровень загрязненности которой может меняться во времени довольно быстро). Поэтому анализ донных отложений представляет большой интерес как для исследования общей загрязненности водоемов, так и для изучения процессов превращения углеводородов и их влияния на биоценоз.

Несмотря на применение высокоэффективных хроматографических и спектрофотометрических методов, разделить и провести полный анализ углеводородов до сих пор не удалось по ряду причин. Отметим из них наиболее важные: 1) сложность состава углеводородов, 2) знания о биосинтезированных углеводородах исчерпываются несколькими классами соединений и ограниченным числом объектов как в географическом, так и во временном отношении; 3) источники загрязнения морской среды углеводородами в результате геохимических процессов и деятельности человека весьма многочисленны и разнообразны.

Данных об углеводородах в донных отложениях Балтийского моря немного, и относятся они к ограниченным географическим регионам. Так, есть данные, что с 1974-1975 гг. по 1982 г. концентрации нефтяных углеводородов (парафино-нафтеновая фракция) в поверхностном слое донных отложений Ботнического залива, собственно Балтики, проливов Зунда, Каттегата и Скагеррака повысились с 199 до 252 мкг на грамм сухого вещества $\left[{ }^{1,2}\right]$. Содержание алифатических углеводородов в Финском заливе и в открытой части Балтийского моря колеблется в пределах $0,1-2,6$ мкг, а ароматических - 4-120 нг на грамм сухого седимента [ $\left.{ }^{3}\right]$. Близкие результаты получены для Финского архипелага [ $\left.{ }^{4}\right]$. Концентрации алифатических и ароматических углеводородов в донных отложениях Южной Балтики различались, по данным восьми станций, в 50-100 раз. В Гданьском заливе суммарная концентрация углеводородов составляла от нескольких до 140 мкг на грамм сухого седимента [5]. Состав углеводородов частично указывал на их терригенную природу, а частично на нефтяное происхождение (высокое содержание флуорантена и пирена в пробах, отобранных на некоторых станциях).

\section{Методика анализа}

Неполярные углеводороды (НУ) выделяли из осадка тремя методами: 1) экстракцией в аппарате Сокслета высушенного осадка, 2) экс-- 
тракцией в аппарате Сокслета мокрого осадка, 3) экстракцией мокрого осадка путем механического перемешивания с декантированием экстрагента после центрифугирования.

В первом случае мокрую навеску 25 г сушили в течение суток при температуре $40^{\circ} \mathrm{C}$ и затем экстрагировали 10 ч смесью $н$-гексана и ацетона $(9: 1)$. Во втором случае навеску $10-20$ г экстрагировали сначала 4 ч ацетоном, а затем 4 ч $H$-гексаном. В третьем случае к $10-20$ г мокрого осадка прибавляли 20 мл ацетона, перемешивали в течение 10 мин и центрифугировали. Ацетон декантировали, процедуру повторяли. Затем осадок дважды экстрагировали описанным способом 20 мл н-гексана. Экстракты соединяли и добавляли 100 мл $2 \%$-ного раствора $\mathrm{Na}_{2} \mathrm{SO}_{4}$. Верхний слой отделяли, растворитель выпаривали.

Очистку экстрактов от полярных соединений проводили в колонке с $\mathrm{Al}_{2} \mathrm{O}_{3}$. Подлежащую дальнейшему исследованию фракцию НУ вымывали 30 мл $\boldsymbol{H}$-гексана. Количественное содержание НУ определяли методом ИК-спектрофотометрии (табл. 1).

\section{Таблица 1}

Содержание неполярных углеводородов в донных отложениях Балтийского моря по данным трех методов экстракции, мкг/г сухого вещества

\begin{tabular}{l|c|r|r}
\hline \multicolumn{1}{c|}{ Метод } & Проба & $c_{\mathrm{cp}}$ & $v, \%$ \\
\hline $\begin{array}{l}\text { Экстракция сухого } \\
\text { осадка }\end{array}$ & $1(n=10)$ & 124,6 & 27,5 \\
& $2(n=2)$ & 102,4 & 28,7 \\
Экстракция мокрого & & & \\
осадка & $1(n=11)$ & 121,3 & 24,1 \\
& $2(n=1)$ & 107,6 & \\
Центрифугирование & $3(n=2)$ & 18,6 & 13,3 \\
& $2(n=1)$ & 121,6 & \\
& $3(n=4)$ & 20,3 & 11,3 \\
& $4(n=7)$ & 9,5 & 34,7
\end{tabular}

Средние выходы экстракции, полученные с использованием трех вышеописанных методов, близки. Вариации результатов первых двух методов также близки и превышают вариацию 3-го метода. Меньшие колебания концентраций при использовании 3-го метода объясняются меньшим числом процедур, необходимых для проведения экстракции, а также примерно в 5 раз меньшим объемом растворителей-экстрагентов. Оба этих обстоятельства уменьшают возможность загрязнения пробы во время экстракции и снижают тем самым значение случайной ошибки. Газохроматографический анализ показал, что составы углеводородов, выделенных из осадка 1-м и 2-м методами, различаются мало. Для углеводородов, выделенных 3-м методом, характерны большее число компонентов и более значительный подъем нулевой линии. Концентрация низкокипящих углеводородов во фракции НУ при использовании 3-го метода также немного выше, чем при экстракции 2-м методом. В дальнейшей работе для выделения углеводородов из донных осадков использовали преимущественно 2-й и 3-й методы.

\section{Результаты и их обсуждение}

Органическое вещество в разных слоях донных отложений водоемов является индикатором, характеризующим среду осаждения. Концентра- 
ция загрязняющих веществ на разных глубинах донных осадков отражает историю загрязнения данного водоема. Содержание в осажденном материале НУ зависит также от типа седимента. Известно, что фоновые концентрации биогенных углеводородов в мелкозернистых илистых и глинистых осадках выше, чем в песчаном материале [ $\left.{ }^{6}\right]$.

Анализы проб, отобранных из донных осадков Финского залива и открытой части Балтики в течение 1979-1985 гг. (табл. 2) показали, что концентрации НУ в верхнем слое донных осадков варьируют более чем в 15 раз и превышают 100 мкг/г сухого осадка на пяти станциях из девяти исследованных. Концентрации НУ резко снижаются с глубиной. Так, на глубине $2,5-5$ см их становится до 5 раз меньше, а на глубине 5,0 7,5 см - до 7 раз меньше, чем в верхнем слое. Самое резкое снижение концентрации НУ приходится на верхние 5 см (рис. 1). Следовательно, здесь превращения углеводородов протекают с наибольшей скоростью.

таблица 2

Содержание неполярных углеводородов в донных отложениях Балтийского моря на различных глубинах залегания

\begin{tabular}{|c|c|c|c|c|}
\hline \multirow{2}{*}{$\begin{array}{l}\text { Номер } \\
\text { станции }\end{array}$} & \multicolumn{2}{|c|}{ Координаты станции } & \multirow{2}{*}{$\begin{array}{c}\text { Глубина отбора } \\
\text { проб, см }\end{array}$} & \multirow{2}{*}{$\begin{array}{l}\text { Средняя концентра- } \\
\text { ция, мкг/г сухого } \\
\text { осадка }\end{array}$} \\
\hline & широта & долгота & & \\
\hline 1 & 2 & 3 & 4 & 5 \\
\hline
\end{tabular}

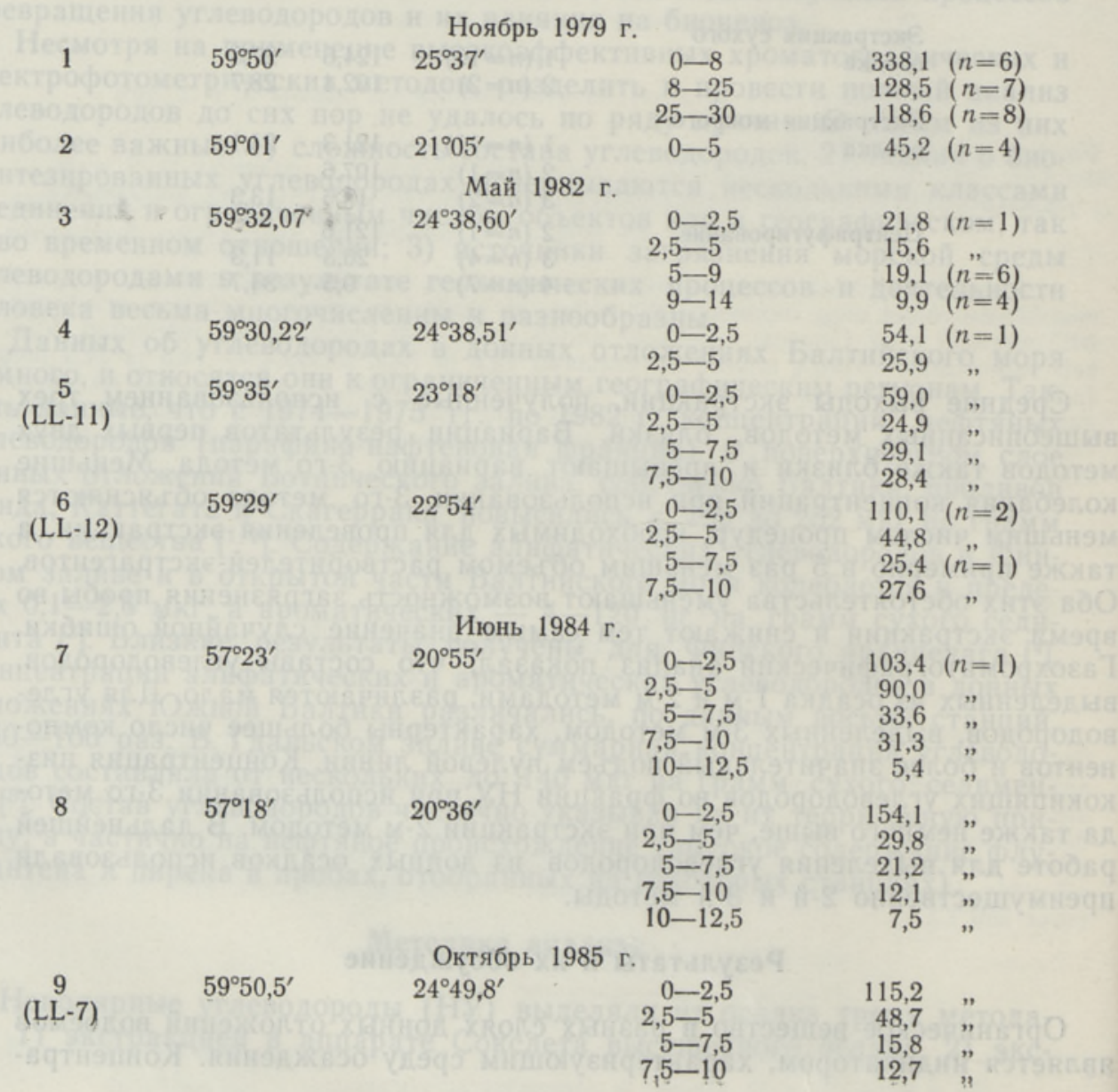




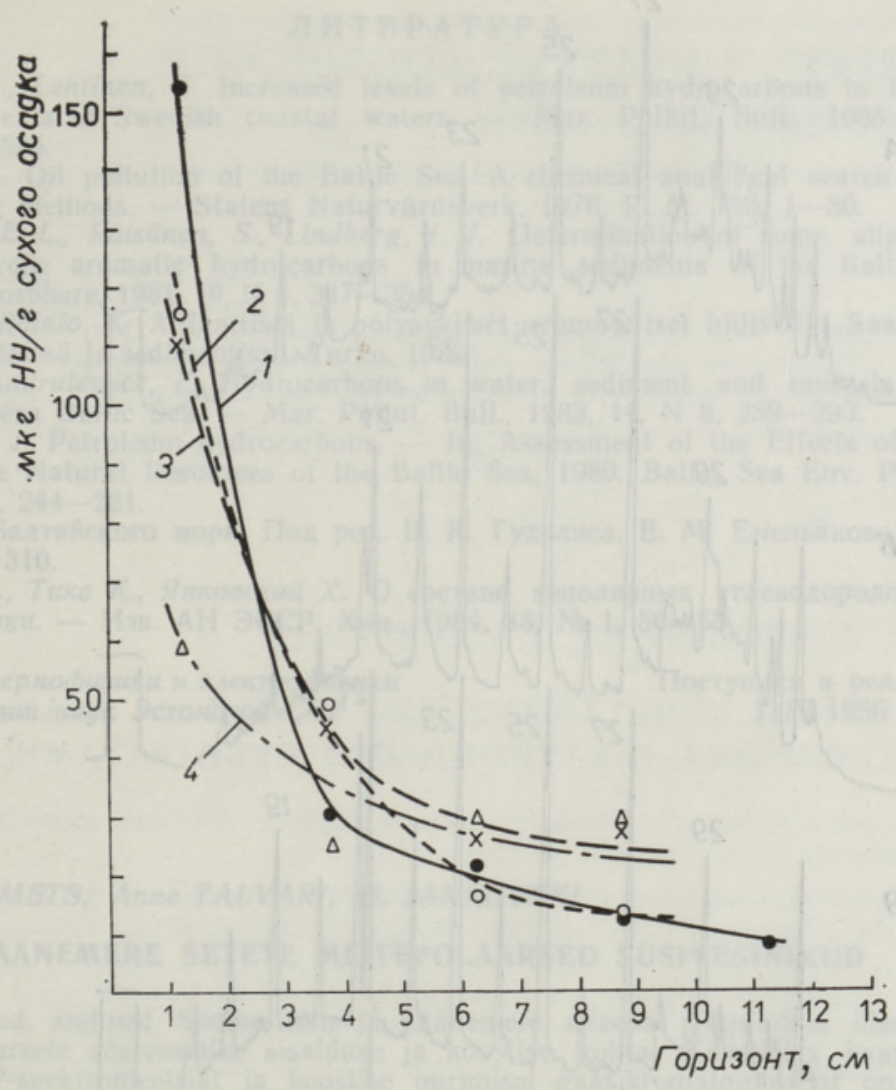

Рис. 1. Зависимость концентрации неполярных углеводородов от глубины горизонта донных отложений. Станции 8 (1), 9 (2), 6 (3) и 5 (4). Координаты станций см. в табл. 2.

Длина $\mu$-алкановых цепей и соотношение четных и нечетных атомов углерода часто используются в качестве показателей происхождения углеводородов. Судя по хроматограммам (рис. 2) донных осадков с 8-й станции, находящейся в Центральной Балтике, среди выделенных НУ преобладают $\boldsymbol{H}$-алканы с нечетным числом атомов углерода, что более характерно для биогенных, чем для нефтяных углеводородов, соотношение $\mathrm{C}_{\text {qетн }} / \mathrm{C}_{\text {нечетн }}<1$. Самым большим является содержание прямоцепочечных углеводородов $\mathrm{C}_{21}-\mathrm{C}_{29}$, характерных для высших растений и свидетельствующих в пользу терригенного происхождения этих соединений. Существенная роль терригенного материала при образовании донных отложений Балтийского моря известна [7]. С глубиной залегания состав НУ упрощается, что отражается на хроматограммах исчезновением подъема нулевой линии в области времен удерживания $\boldsymbol{H}$-алканов $\mathrm{C}_{27}-\mathrm{C}_{32}$. Состав НУ донных осадков значительно отличается от состава НУ воды [ $\left.{ }^{8}\right]$.

\section{Выводы}

1. Содержание неполярных углеводородов в поверхностных слоях донных отложений Балтийского моря сильно варьируется. В илистых осадках, в частности сформировавшихся в условиях дефицита кислорода, их конџентрация нередко превышает 100 мкг/г сухого седимента. 


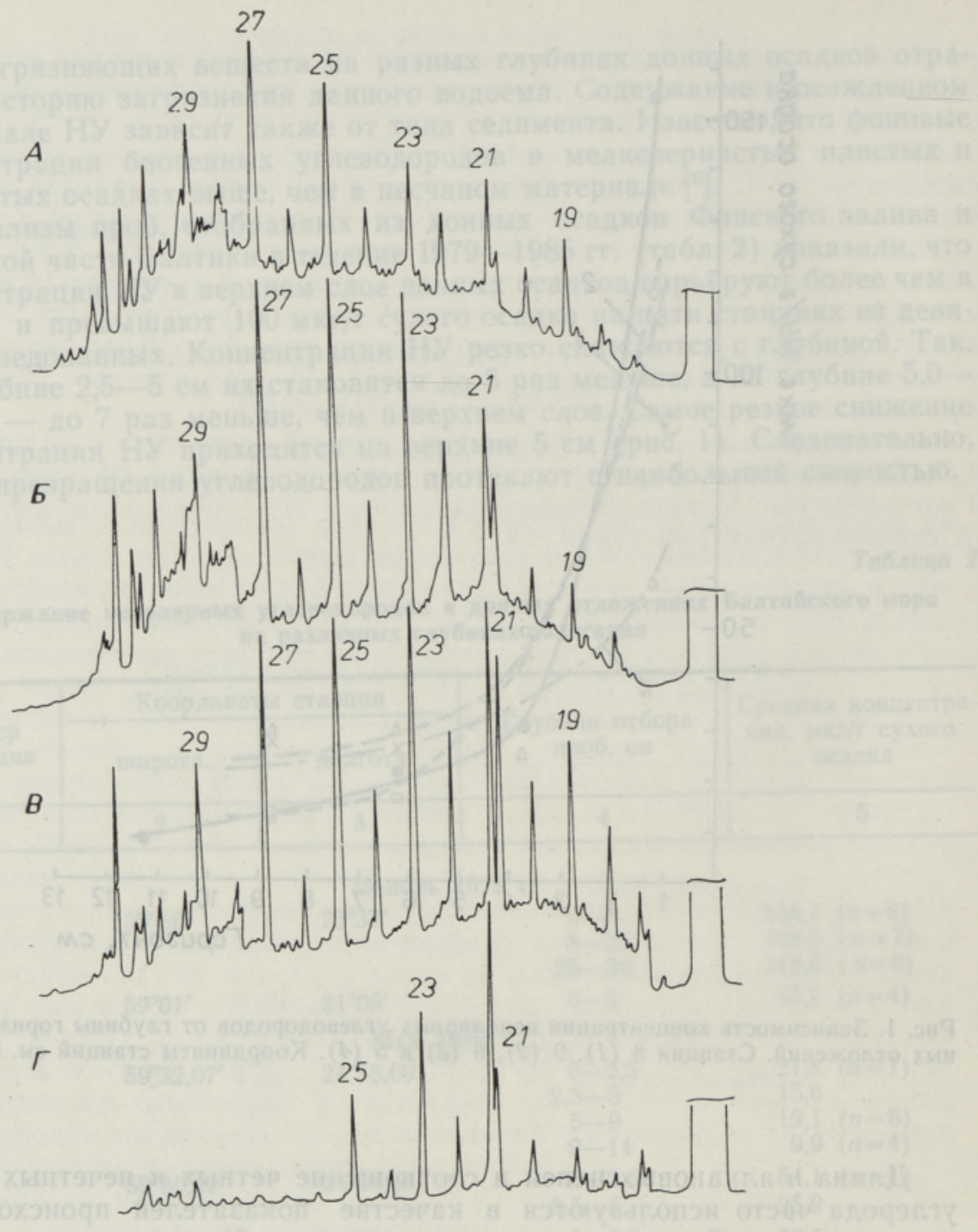

Рис. 2. Хроматограммы неполярных углеводородов, выделенных из донных осадков со станции $8\left(57^{\circ} 18^{\prime} ; 20^{\circ} 36^{\prime}\right)$. Глубина: $0-2,5$ (А), $2,5-5$ (Б), $5-7,5$ (В) и $7,5-$ $10 \mathrm{~cm}(\Gamma)$. Номера над пиками означают число атомов углерода в молекулах н-алканов. Условия хроматографирования: стеклянный капилляр 20 м, неподвижная фаза OV-17, $2,5^{\circ}$ ммин от 90 до $250^{\circ}$, газ-носитель - водород, пламенно-ионизационный детектор.

2. С глубиной залегания концентрация неполярных углеводородов уменьшается, причем особенно резко в верхних 5 см, а углеводородный состав упрощается.

3. н-Алканы, выделенные из донных осадков Балтийского моря, характеризуются преобладанием нечетных атомов углерода $\mathrm{C}_{21}-\mathrm{C}_{29}$ $\left(\mathrm{C}_{\text {четн }} / \mathrm{C}_{\text {нечетн }}<1\right)$, что свидетельствует об их терригенном происхождении, 
1. Mattson, J., Lehtinen, C. Increased levels of petroleum hydrocarbons in the surface sediments of Swedish coastal waters. - Mar. Pollut. Bull., 1985, 16, N 10, $390-395$.

2. Rudling, L. Oil pollution of the Baltic Sea. A chemical analytical search for monitoring methods. - Statens Naturvårdsverk, 1976, P. M. 783, $1-80$.

3. Poutanen, E.-L., Räisänen, S., Lindberg, J. J. Determination of some aliphatic and polycyclic aromatic hydrocarbons in marine sediments of the Baltic Sea. Chemosphere, 1981, 10, N 4, 347-354.

4. Linko, R., Rainio, $K$. Alifaattiset ja polysykliset aromaattiset hilivedyt Saaristomeren vesieliöissä ja sedimentissä. Turku, 1980.

5. Law, R., Andrulewicz, E. Hydrocarbons in water, sediment and mussels from the Southern Baltic Sea. - Mar. Pollut. Bull., 1983, 14, N 8, 289-293.

6. Strömberg, J. Petroleum hydrocarbons, - In: Assessment of the Effects of Pollution on the Natural Resources of the Baltic Sea, 1980. Baltic Sea Env. Proc., 1981, N 5B, 244-261.

7. Геология Балтийского моря. Под ред. В. К. Гуделиса, Е. М. Емельянова. Вильнюс, $1976,310$.

8. Талвари А., Тикс K., Янковский X. О составе неполярных углеводородов в водах Балтики. - Изв. АН ЭССР. Хим., 1984, 33, № 1, 50-55.

Институт термофизики и электрофизики Академии наук Эстонской ССР
Поступила в редакцию $11 / \mathrm{V} 1986$

\section{Kadri LAANEMETS, Anne TALVARI, H. JANKOVSKI}

\section{LÅANEMERE SETETE MITTEPOLAARSED SUSIVESINIKUD}

On esitatud andmed Soome lahe ja Läänemere avaosa põhjasetete ülemiste kihtide mittepolaarsete süsivesinike sisalduse ja koostise kohta. Kasutades kvantitatiivsel määramisel IP-spektromeetriat ja koostise uurimisel gaasikromatograafiat on leitud, et pōhjasetete pinnakihtides, eriti neis, mis on moodustunud hapniku defitsiidi tingimustes, ületab süsivesinike kontsentratsioon sageli $100 \mu \mathrm{g}$ grammi kuiva sette kohta. Sette sügavamates kihtides mittepolaarsete süsivesinike kontsentratsioon väheneb, kusjuures eriti järsult ülemises 5-sentimeetrises kihis, süsivesinike koostis aga muutub lihtsamaks. Põhjasetetest eraldatud n-alkaanides on ülekaalus paaritu süsinikuaatomite arvuga ühendid. $n$-alkaanide $\mathrm{C}_{21}-\mathrm{C}_{29}$ suured kontsentratsioonid vōimaldavad oletada mittepolaarsete süsivesinike terrigeenset päritolu.

\section{Kadri LAANEMETS, Anne TALVARI, H. JANKOVSKI}

\section{NON-POLAR HYDROCARBONS IN BALTIC SEDIMENTS}

Data on non-polar hydrocarbon concentration and composition in upper layers of the Finnish Bay and the open Baltic sediments are presented. Using IR-spectrophotometry for the quantitative determination and gas chromatography for the analysis of hydrocarbons it was ascertained that non-polar hydrocarbon concentrations exceeding $100 \mu \mathrm{g} / \mathrm{g} \mathrm{d}$.w. in bottom sediments, particularly in silt-clays formed in oxygen deficiency are quite frequent. In deeper sediment layers the concentration of hydrocarbons decreases, most rapidly in the upper 5 -cm layer, and the composition is less complex. In $n$-alkanes of sediments odd carbon number compounds prevail. High concentration of $\mathrm{C}_{21}-\mathrm{C}_{29}$ in $n$-alkanes may serve as the indication of the terrestrial origin of hydrocarbons of the Baltic sediments. 